\title{
Chemical Modification of Fluorinated Self- Assembled Monolayer Surfaces by Low Energy Reactive Ion Bombardment
}

\author{
T. Pradeep,* B. Feng, T. Ast, J. S. Patrick, and R. G. Cooks \\ Department of Chemistry, Purdue University, West Lafayette, Indiana, USA \\ S. J. Pachuta \\ 3M Corporate Research Laboratories, 201-2S-16 3M Center, St. Paul, Minnesota, USA
}

\begin{abstract}
Reactive collisions of low energy $(<100-\mathrm{eV})$ mass-selected ions are used to chemically modify fluorinated self-assembled monolayer surfaces comprised of alkanethiolate chains $\mathrm{CF}_{3}\left(\mathrm{CF}_{2}\right)_{11}\left(\mathrm{CH}_{2}\right)_{2} \mathrm{~S}-$ bound to Au. Typical experiments were done by using $1-\mathrm{nA} / \mathrm{cm}^{2}$ beams and submonolayer doses of reactant ions. Characterization of the modified surface was achieved by in situ chemical sputtering $\left(60-\mathrm{eV} \mathrm{Xe}^{+\cdot}\right)$ and by independent high mass resolution time-of-flight-secondary ionization mass spectrometry (TOF-SIMS) (15-25-keV, $\mathrm{Ga}^{+}$) experiments. Treatment with $\mathrm{Si}^{35} \mathrm{Cl}_{4}^{+\cdot}$ produced a surface from which $\mathrm{Xe}^{+\cdot}$ sputtering liberated $\mathrm{CF}_{2}{ }^{35} \mathrm{Cl}^{+}$ions, which suggested $\mathrm{Cl}$-for-F halogen exchange at the surface. Isotopic labeling studies that used $\mathrm{Si}^{35} \mathrm{Cl}_{2}^{37} \mathrm{Cl}_{2}^{+}$, and experiments with bromine-containing and iodine-containing projectiles, confirmed this reaction. High mass resolution TOF-SIMS spectra, as well as high spatial resolution images, provided further evidence as to the existence of halogen-exchanged species at the bombarded surface. Analogous $\mathrm{Cl}-$ for-F halogen substitution was observed in a model gas-phase reaction. The ion-surface reaction is suggested to proceed through an intermediate fluoronium ion in which the projectile is bonded to the target molecule. The most significant conclusion of the study is that selective chemical modification of monolayer surfaces can be achieved by using reactive ion beams, which lead to new covalent bonds at the surface and in the scattered ions. (J Am Soc Mass Spectrom 1995, $6,187-194)$
\end{abstract}

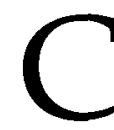
hemical modification of surfaces can be achieved by a number of methods. These methods range from exposure to chemical reagents in solution or the vapor phase to more specific treatments, which include ion beam implantation [1-3], molecular beam scattering $[4,5]$, and plasma etching $[6,7]$. The collisions of atoms, molecules, and ions with surfaces are of particular interest for controlled surface chemical modification. Selection of an appropriate atomic, molecular, or ionic reagent, at the optimum collision energy, should make it possible to achieve selective chemical modification of the outermost atomic monolayers of a surface. If such modifications are made to selected areas of the surface, a form of highly specific chemical writing of high spatial resolution might be developed. In spite of its technological appeal, this

Address reprint requests to Dr. R. G. Cooks, Department of Chemistry, Purdue University, West Lafayette, IN 47907.

* On leave from Regional Sophisticated Instrumentation Center and Department of Chemistry Indian Institute of Technology, Madras 600 036 , India. objective has been explored surprisingly little, in part because of the difficulty in creating appropriate beams of neutral reagents in sufficient flux at the necessary energies, and in part because there has been relatively little interest in the topic of low energy collisions of polyatomic organic ions with surfaces. This is in contrast to corresponding studies that involve monoatomic or diatomic ion collisions, a subject recently reviewed by Rabalais and co-workers [8]. Reactive molecular beam scattering has been of interest to Ceyer [9] and others [10] who have studied the changes produced at the surface, in addition to changes in the scattered beam. Jacobs and co-workers [11] and others [12, 13] have performed increasingly elegant studies of ion beam scattering, but the effects on the surface have been a secondary concern.

Ion-surface inelastic collisions are well known as a means of effecting dissociation of mass-selected ions and this procedure, termed surface-induced dissociation (SID), has been implemented on mass spectrometers of several types [14-23]. In the course of these 
studies, reactive collisions often have been observed. Early studies showed that fluorine atoms can be picked up from the surface by ionized metal carbonyls, whereas hydrogen and alkyl group abstraction often was observed by aromatic and other ions [23-26]. Recently, a systematic study of some transition metal projectiles, as well as of a large number of group IIIA to VIIA atomic projectiles, revealed that $\mathrm{MF}_{m}^{+}(m=$ 1-5) scattered products readily are observed upon collisions of atomic ions at fluorinated self-assembled monolayer (F-SAM) surfaces [27, 28]. By changing the nature of the surface and the scattering conditions, much is being learned about the mechanisms of these reactive scattering processes through study of the reactively scattered ions. The present paper also is concerned with reactive collisions of low energy $(<100-$ $\mathrm{eV})$ projectile ions at F-SAM surfaces, but attention is given to characterization of the chemically modified surface, rather than to the scattered ionic product, as was the case in previous work.

Surface modification is an almost inevitable consequence of abstraction of an atom from the surface by a projectile ion because a radical site is generally created. This radical may be stabilized by (1) elimination of an atom or group, which leads to the formation of an unsaturated bond, (2) reaction with an adsorbate molecule, or (3) reaction with an adjacent surfacebound chain to cause chain linking and radical propagation. If dissociation of the projectile occurs at the surface, a neutral fragment from this reaction is another candidate to become attached to the radical site.

\section{Experimental}

Fluorinated SAM surfaces $\mathrm{CF}_{3}\left(\mathrm{CF}_{2}\right)_{11}\left(\mathrm{CH}_{2}\right)_{2} \mathrm{~S}-\mathrm{Au}$, were provided by $\mathrm{C}$. E. D. Chidsey; details of their preparation and properties are reported elsewhere [29, 30]. The surfaces were rinsed with hexane and air-dried before use. A fresh surface was used in each new experiment. All chemicals were from Aldrich (Milwaukee, WI) and were used as received. The ion-surface reaction experiments were studied in a custom-built, hybrid mass spectrometer of BEEQ geometry $(\mathrm{B}=$ magnetic sector, $\mathrm{E}=$ electric sector, and $\mathrm{Q}=$ quadrupole mass analyzer) [31]. The projectile ions, generated by electron impact $\left(70 \mathrm{eV}, 10^{-5}\right.$ torr sample pressure), were mass and energy selected by using the $B$ and $E$ fields, respectively, and then decelerated to $60-\mathrm{eV}$ laboratory translational energy for collision with the surface in the scattering chamber maintained at or below $10^{-8}$ torr. The incident angle was fixed at $55^{\circ}$ with respect to the surface normal and the scattering angle was $90^{\circ}$ with respect to the incident beam direction. The primary ion current density was 1 $\mathrm{nA} / \mathrm{cm}^{2}$ and the spot size was about $3 \mathrm{~mm}^{2}$. Typical bombardment times for surface modification ranged from $20 \mathrm{~min}$ to $2 \mathrm{~h}$. Assuming $10^{14}$ ions $/ \mathrm{cm}^{2}$ as the monolayer coverage, total ion doses of $20-\mathrm{min}$ to $2 \mathrm{~h}$ bombardment correspond to 0.1 to 0.5 monolayer de- position. Scattered ion mass spectra were recorded by scanning the quadrupole mass analyzer, with the secondary ion electrostatic analyzer operated to maximize detected scattered ion current. Chemical sputtering $[32,33]$ with $60-\mathrm{eV}^{132} \mathrm{Xe}^{+\cdot}$ as the projectile ion, was applied to examine the surface composition before and after prolonged reactive ion bombardment. Some surfaces also were examined by high resolution time-offlight secondary ionization mass spectrometry (TOFSIMS) via a Charles Evans \& Associates TFS series instrument (Redwood City, CA). Both high mass resolution spectra ( $\left.15 \mathrm{keV}, \mathrm{Ga}^{+}\right)$and high spatial resolution images $\left(25 \mathrm{keV}, \mathrm{Ga}^{+}\right)$were recorded. The static SIMS limit was not approached in these experiments. The samples were analyzed by TOF-SIMS some 2 days after bombardment in the BEEQ instrument. During this period, they were exposed to air, but the possible effects of this exposure were not studied. However, the F-SAM surfaces themselves have been shown to be unaffected by prolonged exposure to air [30]. Similarities were sought between the reactions that occur in ion-surface reactions and model ion-molecule reactions. For this purpose, a triple quadrupole mass spectrometer, Finnigan-MAT TSQ 700 (San Jose, CA) was used to examine the gas-phase ion-molecule reactions. Mass-selected projectile ions, produced by $70-\mathrm{eV}$ electron impact ionization, were allowed to react with perfluorohexane ( $1 \mathrm{mtorr}$ ) at a nominal 2-eV laboratory collision energy in the second (rf-only) quadrupole. Product ions were recorded by scanning the third quadrupole.

\section{Results and Discussion}

Silicon-containing ions, like many other monatomic or polyatomic ions [28], undergo reactive scattering from fluorinated SAM surfaces and fluorine is incorporated into the scattered products. For example, $\mathrm{SiCl}_{n}^{+}(n=$ $0-4)$ at laboratory collision energies between 20 and 60 $\mathrm{eV}$ yields scattered ions that include products due to (1) chemical sputtering, for example, $\mathrm{C}_{3} \mathrm{~F}_{5}^{+}$; (2) surface-induced dissociation, for example, $\mathrm{SiCl}^{+}$, as well as (3) products due to ion-surface reactions, for example, $\mathrm{SiF}^{+}, \mathrm{SiClF}^{+}$, and $\mathrm{SiCl}_{2} \mathrm{~F}^{+}$(Figure 1). Chemical sputtering products, $\mathrm{C}_{n} \mathrm{~F}_{m}^{+}(n=1-3, m=1-5)$, are most pronounced at higher collision energies, that is, above $40 \mathrm{eV}$; however, SID and ion-surface reaction products are generated efficiently even at lower collision energy. The reactively scattered ions $\mathrm{SiF}^{+}, \mathrm{SiClF}^{+}$, and $\mathrm{SiCl}_{2} \mathrm{~F}^{+}$all contain fluorine derived from the surface. The occurrence of fluorine abstraction suggests that changes in the final chemical state of the surface must occur as a result of ion bombardment.

To investigate the changes that the reactive species have caused to the chemical nature of the surface, the surface itself must be characterized. Chemical sputtering mass spectra allow surface characterization because they reflect processes in which ionized fragments from the surface itself, or from an adsorbate, are 


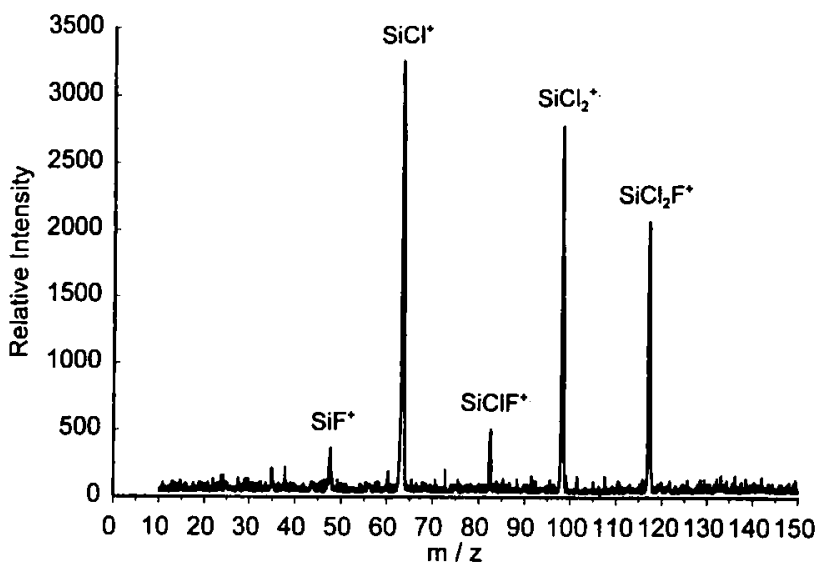

Figure 1. Scattered ion mass spectrum recorded upon 20-eV collision of a Si${ }^{35} \mathrm{Cl}_{2}^{+\cdot}$ projectile at a fluorinated SAM surface. Note the appearance of ion-surface reaction products $\mathrm{SiCl}_{2} \mathrm{~F}^{+}$, $\mathrm{SiClF}^{+}$, and $\mathrm{SiF}^{+}$.

ejected following a charge exchange process [32]. Therefore, chemical sputtering spectra were taken before and after prolonged ion bombardment with $\mathrm{SiCl}_{n}^{+}$ beams. These spectra were obtained by using $60-\mathrm{eV}$ $\mathrm{Xe}^{+\cdot}$ projectiles and they displayed changes induced at the surface as a result of prolonged reactive ion bombardment. For example, prior to $\mathrm{Si}^{35} \mathrm{Cl}_{4}^{+\cdot}$ ion beam bombardment of the surface, no feature at $\mathrm{m} / \mathrm{z} 85$ $\left(\mathrm{CF}_{2}{ }^{35} \mathrm{Cl}^{+}\right)$could be observed in the $\mathrm{Xe}^{+\cdot}$ chemical sputtering experiment; however, $\mathrm{CF}_{2}{ }^{35} \mathrm{Cl}^{+}$ion was clearly observed after a 2-h surface exposure to a $60-\mathrm{eV}$ $\mathrm{Si}^{35} \mathrm{Cl}_{4}^{+\cdot}$ ion beam. This result was confirmed by an isotopic study via a $\mathrm{Si}^{35} \mathrm{Cl}_{2}^{37} \mathrm{Cl}_{2}^{+\cdot}$ projectile, and again attention was focused on the changes in the pattern of ions observed in the chemical sputtering spectra recorded before and after ion bombardment (Figure 2). Typical $60-\mathrm{eV} \mathrm{Xe}^{+\cdot}$ chemical sputtering peaks, $\mathrm{CF}^{+}$ $\left(m / z\right.$ 31), $\mathrm{CF}_{2}^{+\cdot}(m / z 50), \mathrm{CF}_{3}^{+}(m / z 69), \mathrm{C}_{2} \mathrm{~F}_{3}^{+}(m / z$ $81)$, and $\mathrm{C}_{3} \mathrm{~F}_{3}^{+}(m / z 93)$, were observed in both spectra, with some variation in intensity. Before $\mathrm{Si}^{35} \mathrm{Cl}_{2}{ }^{37} \mathrm{Cl}_{2}^{+\cdot}$ bombardment, a low intensity peak, which may be due to an impurity, appeared at $m / z$ 85 , whereas no peak at $m / z \quad 87$ was observed (Figure 2a). After ion beam bombardment, peaks at $\mathrm{m} / \mathrm{z} 85$ and 87 in roughly equal abundance were recorded (Figure $2 \mathrm{~b}$ ). This result suggests, although it does not conclusively prove, that the peaks are due to $\mathrm{CF}_{2}{ }^{35} \mathrm{Cl}^{+}$ and $\mathrm{CF}_{2}{ }^{37} \mathrm{Cl}^{+}$, respectively. The presence of these peaks indicates that the chemical conversion of $-\mathrm{CF}_{3}$ groups to $-\mathrm{CF}_{2} \mathrm{Cl}$ groups on the surface might have occurred upon reactive ion beam bombardment.

Static secondary ion mass spectrometry (SSIMS) has been used in characterization of SAM surfaces [34, 35]. Its advantages include high sensitivity, high mass and spatial resolution, and the ability to detect submonolayer quantities of organic materials. High resolution TOF-SIMS spectra via $15-\mathrm{keV} \mathrm{Ga}^{+}$ion bombardment further verified the results for the $\mathrm{Si}^{35} \mathrm{Cl}_{2}{ }^{37} \mathrm{Cl}_{2}^{+\cdot}$ treated surface; they showed the expected exact masses and
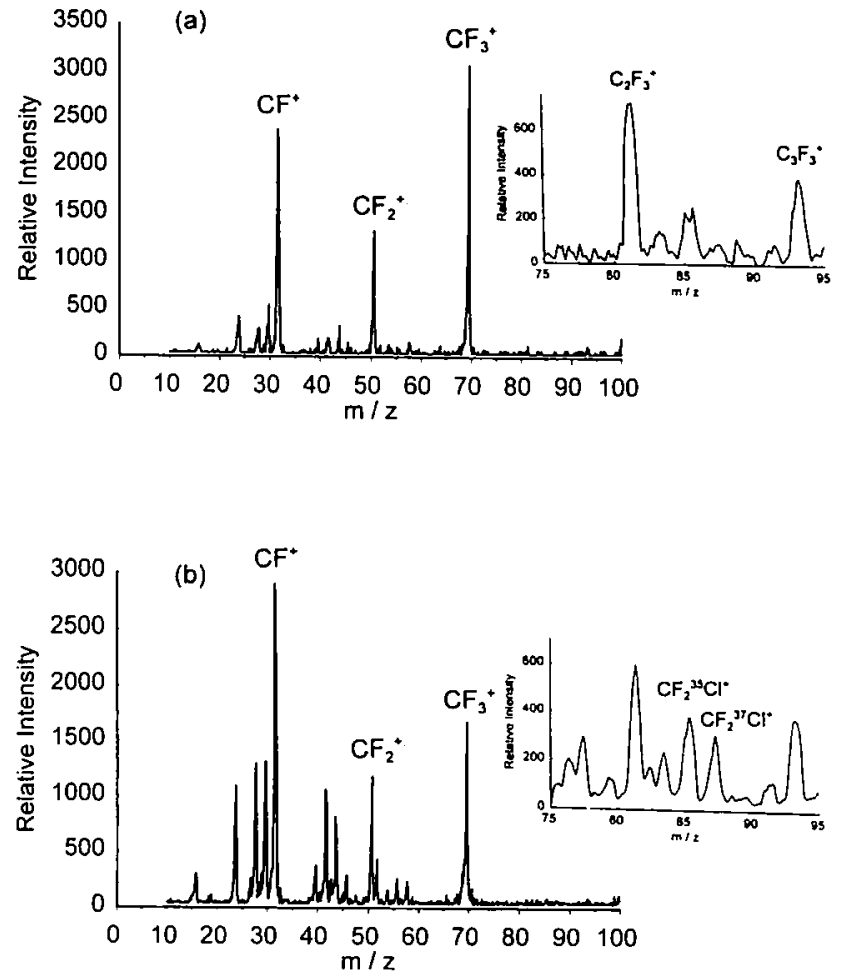

Figure 2. Chemical sputtering spectra recorded upon 60-eV collision of ${ }^{132} \mathrm{Xe}^{+\cdot}$ at a fluorinated SAM surface (a) before and (b) after bombardment with $60-\mathrm{eV} \mathrm{Si}{ }^{35} \mathrm{Cl}_{2}{ }^{37} \mathrm{Cl}_{2}^{++}$projectile for 2 h. Insets show portions of the spectra at high gain. Note the appearance of peaks at $m / z 85$ and 87 in (b). Peaks at $m / z 81$ and 93 are due to chemical sputtering (see text).

isotopic abundance ratios (Figure 3 ). The peaks due to Cl-for-F substitution again appear at the value of $m / z$ 85 and 87 . Note the doublet at the nominal value of $m / z 81$; the low mass peak is due to $\mathrm{C}_{2} \mathrm{~F}_{3}^{+}$(sputtering of the SAM surface), whereas the high mass peak originates from the hydrocarbon adsorbate $\left(\mathrm{C}_{6} \mathrm{H}_{9}^{+}\right)$. Low energy ion bombardment of surfaces may create radical sites in situ, which simultaneously or subsequently react with species that are generated by surface collision processes, including ion-surface reactions, SID, and chemical sputtering. The annealing of either ionic, radical, or neutral species to the F-SAM surface reactive sites would alter the chemical composition of the functional groups at the outermost atomic layers. Such chemical changes can be permanent if new covalent bonds (in this case, $\mathrm{C}-\mathrm{Cl}$ ) are formed while old covalent bonds $(\mathrm{C}-\mathrm{F})$ are broken. The net result of such bond forming and breaking in this case is halogen exchange. A possible mechanism of halogen exchange is proposed in Scheme I, which illustrates reactions between a F-SAM surface, simplified as $\mathrm{RC}_{2} \mathrm{~F}_{5}$, and a $\mathrm{SiCl}_{2}^{+\cdot}$ projectile ion. Upon collision, the unsaturated projectile can form a $\mathrm{Si}-\mathrm{F}-\mathrm{C}$ bond at the terminal $-\mathrm{C}_{2} \mathrm{~F}_{5}$ group through a positively charged fluoronium ion. Subsequent fluorine transfer from an adjacent $\mathrm{C}-\mathrm{F}$ bond to the silicon will result in a new $\mathrm{Si}-\mathrm{F}$ bond and leaves a free radical site at 


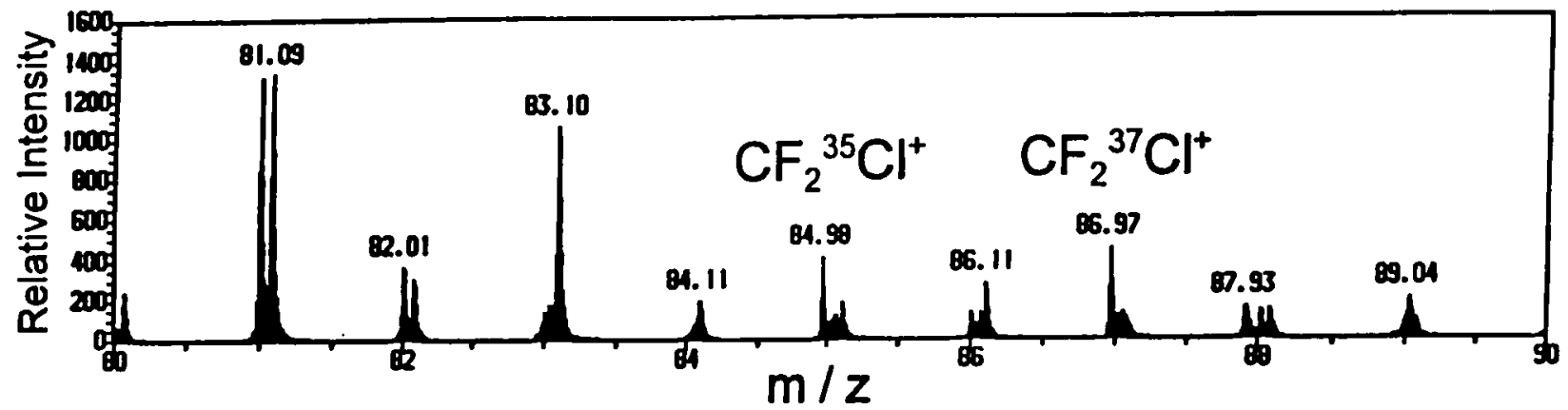

Figure 3. High resolution TOF-SIMS spectrum ( $\left.15 \mathrm{keV}, \mathrm{Ga}^{+}\right)$of a fluorinated SAM surface after bombardment with $60-\mathrm{eV} \mathrm{Si}^{35} \mathrm{Cl}_{2}{ }^{37} \mathrm{Cl}_{2}^{+}$projectile for $2 \mathrm{~h}$. The mass scale calibration was done by selecting peaks of known identity (e.g., $\mathrm{CF}^{+}, \mathrm{CF}_{3}^{+}$, and $\mathrm{C}_{2} \mathrm{~F}_{5}^{+}$).

carbon. The intermediate thus formed is composed of two moieties, again bonded together through a fluoronium ion. This intermediate can dissociate to yield either (a) a surface-bound radical and a scattered product ion $\mathrm{SiCl}_{2} \mathrm{~F}^{+}$or (b) a surface-bound olefin and an unstable gaseous ion $\mathrm{SiCl}_{2} \mathrm{~F}_{2}^{+}$, which may fragment to give observed scattered products $\mathrm{SiClF}^{+\cdot}$ and $\mathrm{SiCl}_{2} \mathrm{~F}^{+}$. The fluoronium intermediate may also rearrange to form a $\mathrm{C}-\mathrm{Cl}$ bond that leads to (c) the formation of $\mathrm{SiClF}^{+\cdot}$ and the $\mathrm{Cl}-$ for- $\mathrm{F}$ modified surface. The observation of the chemical sputtering product $\mathrm{CF}_{2} \mathrm{Cl}^{+}$indicates that the chlorine is most likely bonded to the outermost carbon of the fluoroalkyl chain.

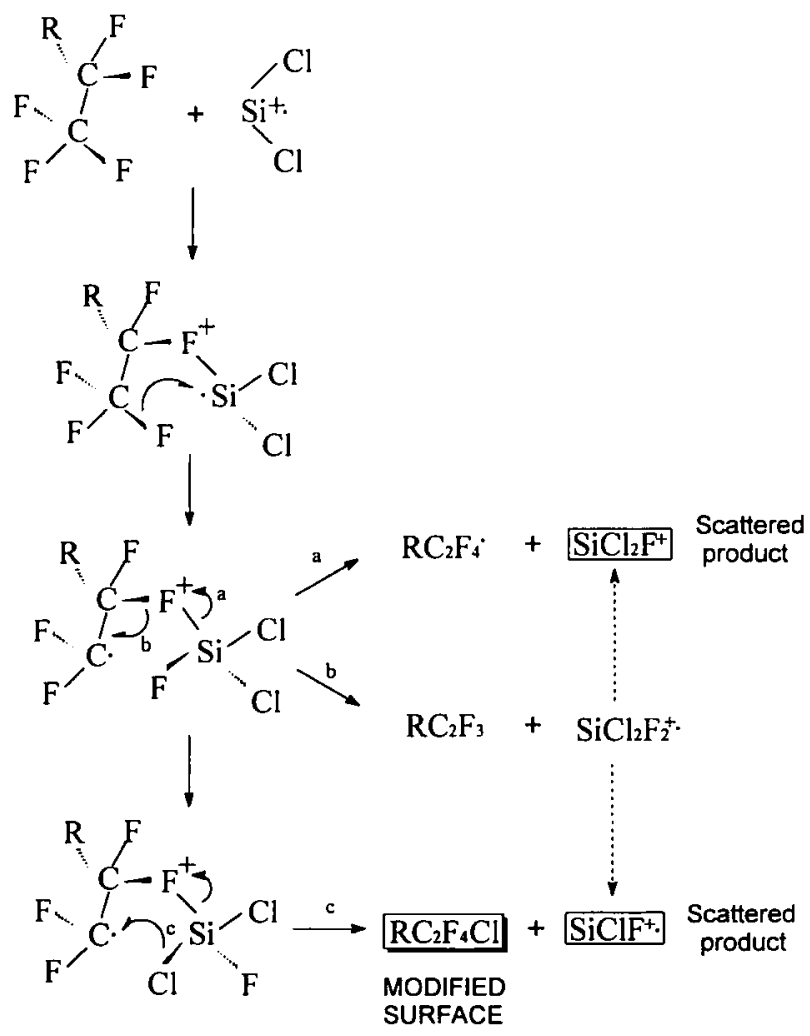

Scheme I. Possible mechamism for halogen exchange between $\mathrm{SiCl}_{2}^{+\cdot}$ and a fluorinated SAM surface $\left(\mathrm{RC}_{2} \mathrm{~F}_{5}\right)$.
There are a number of additional mechanistic issues that need attention. The illustrated mechanism implies that the fluoronium ion in the reactive intermediate binds at the second carbon of the fluoroalkyl chain, whereas the free radical site is at the terminal carbon. This allows the chlorine of the projectile to attach to this carbon without further halogen exchange or rearrangement. It is also possible that the fluoronium ion is initially generated at the terminal carbon, which creates a radical site at the adjacent carbon atom. In this case, chlorine from the projectile is most probably bonded to the second carbon before it undergoes rearrangement and halogen exchange to yield $\mathrm{CF}_{2} \mathrm{Cl}^{+}$ions. Although the foregoing mechanistic suggestions are consistent with the experimental results, it is not claimed that alternative possibilities can be excluded. However, projectile penetration more deeply into the SAM structure at the collision energies employed seems highly unlikely; even at 500-eV Xe ${ }^{+\cdot}$ energy, the sampling was suggested to be limited to the uppermost portion of the SAM chains [35]. Another possibility is that instead of involving two carbons on the same chain, the silicon species may bridge across two adjacent fluoroalkyl chains. After the elimination of the $\mathrm{Cl}-\mathrm{Si}-\mathrm{F}^{+}$moiety, a $\mathrm{C}-\mathrm{C}$ single bond might then form between the two chains. The cleavage of $\mathrm{C}-\mathrm{F}$ and $\mathrm{C}-\mathrm{Cl}$ bonds, with concomitant formation of a $\mathrm{C}-\mathrm{C}$ bond, is energetically more favorable than the formation of one $\mathrm{C}=\mathrm{C}$ double bond between two carbons of the same chain. However, this linkage would significantly distort the orientation of both chains, because the spacing between unlinked chains in this type of F-SAM is around $6 \AA$ [36] whereas the $\mathrm{C}-\mathrm{C}$ bond length is about $1.5 \AA$. This cross chain $\mathrm{C}-\mathrm{C}$ bond formation does not lead to the proposed halogen exchange at the surface, but it might be a competitive process that affects the outcome of surface modification.

The proposed mechanism accounts for all experimental observations; nevertheless, more direct evidence is needed to confirm that it does take place and that a covalent $\mathrm{C}-\mathrm{Cl}$ bond has indeed been formed. 
We are currently investigating the probability of obtaining such information through techniques like electron energy loss spectroscopy. On the other hand, some alternative mechanisms can be ruled out based on the experimental evidence already available. For example, the possibility that $\mathrm{SiCl}_{4}^{+\cdot}$ projectiles decompose at the surface to form $\mathrm{Cl}$ and $\mathrm{Si}$ atoms and that upon sputtering with $\mathrm{Xe}^{+*}, \mathrm{CF}_{2}^{+\cdot}$ and $\mathrm{Cl}$ species recombine in the gas phase to produce $\mathrm{CF}_{2} \mathrm{Cl}^{+}$does not seem likely because $\mathrm{CF}_{2}^{+}$and $\mathrm{CF}_{3}^{+}$are much more abundant as sputtered surface fragments, and yet their products with $\mathrm{Cl}$ atoms are not observed. Also, if $\mathrm{Si}$ were adsorbed at the surface, there should be some $\mathrm{Si}^{+\cdot}$ or $\mathrm{SiF}^{+}$observed in the products [28]; none has been found in either $\mathrm{Xe}^{+\cdot}$ sputtering or TOF-SIMS experiments. Similar arguments could be put forward against a mechanism that involves adsorption of $\mathrm{SiCl}_{4}^{+*}$ or other silicon-containing species at the surface.

Surface bombardment with ions that contain halogens other than chlorine was performed in an attempt to generalize the reaction. In an experiment in which the fluorinated surface was bombarded with $\mathrm{CH}_{2}{ }^{79} \mathrm{Br}^{+}$ and $\mathrm{C}^{81} \mathrm{Br}^{+}$projectile ions (mass selected from $\mathrm{CH}_{2} \mathrm{Br}_{2}$ as a doublet at $m / z$ 93) for $2 \mathrm{~h}$, a new peak at $m / z$ 129 , which represents ${ }^{79} \mathrm{BrCF}_{2}^{+}$, appeared in the subsequent $60-\mathrm{eV} \mathrm{Xe}^{+\cdot}$ chemical sputtering spectrum (Figure 4). Although the peak at $m / z 131$ is largely due to $\mathrm{C}_{3} \mathrm{~F}_{5}{ }^{+}$, a product of chemical sputtering of the surface, there is also a small contribution to the peak from ${ }^{81} \mathrm{BrCF}_{2}^{+}$species. This is consistent with the fact that $m / z 93$ projectile ions consist of $90 \% \mathrm{CH}_{2}{ }^{79} \mathrm{Br}^{+}$and $10 \% \mathrm{C}^{81} \mathrm{Br}^{+}$, as judged from the $70-\mathrm{eV}$ electron impact mass spectrum of $\mathrm{CH}_{2} \mathrm{Br}_{2}$. In another experiment, a copper grid ( 50 mesh, 0.01 -in wire diameter) was placed in front of the surface during the 2-h bombardment. TOF-SIMS images for the $\mathrm{CH}_{2}{ }^{79} \mathrm{Br}^{+}$bombarded surface showed that bromine was higher in intensity in exposed areas than in covered areas; by contrast, the intensity of fluorocarbon species, such as $\mathrm{CF}_{3}^{-}$, was lower in exposed areas (Figure 5). When $\mathrm{CH}_{2}{ }^{81} \mathrm{Br}^{+}$ $(\mathrm{m} / \mathrm{z} 95)$ was used as the projectile ion under identical conditions, the peak at $m / z 129\left({ }^{79} \mathrm{BrCF}_{2}^{+}\right)$disappeared, as expected, whereas the peak at $m / z 131$ increased noticeably in abundance. Analogous experiments that used $\mathrm{CH}_{2} \mathrm{I}_{2}^{+\cdot}$ as the projectile gave the corresponding product $\mathrm{CF}_{2} \mathrm{I}^{+}$, the presence of which also was confirmed by high resolution TOF-SIMS. The foregoing studies provide further support for the conclusion that the outermost portion of a fluorinated self-assembled monolayer surface can be modified to yield $-\mathrm{CF}_{2} \mathrm{X}$ groups by reactive ion bombardment.

The chemical nature of the projectile, as well as the surface exposure time, also affects the outcome of surface modification experiments. For example, by using $\mathrm{P}^{35} \mathrm{Cl}_{3}^{+\cdot}$ as the projectile, the sputtering product diagnostic of $\mathrm{Cl}$-for- $\mathrm{F}$ halogen exchange namely, $\mathrm{CF}_{2} \mathrm{Cl}^{+}(\mathrm{m} / \mathrm{z}$ 85), was observed after 20 -min bombardment (Figure 6). Although the peak at $m / z 85$ also could be due to $\mathrm{PClF}^{+}$, the fact that no peak that
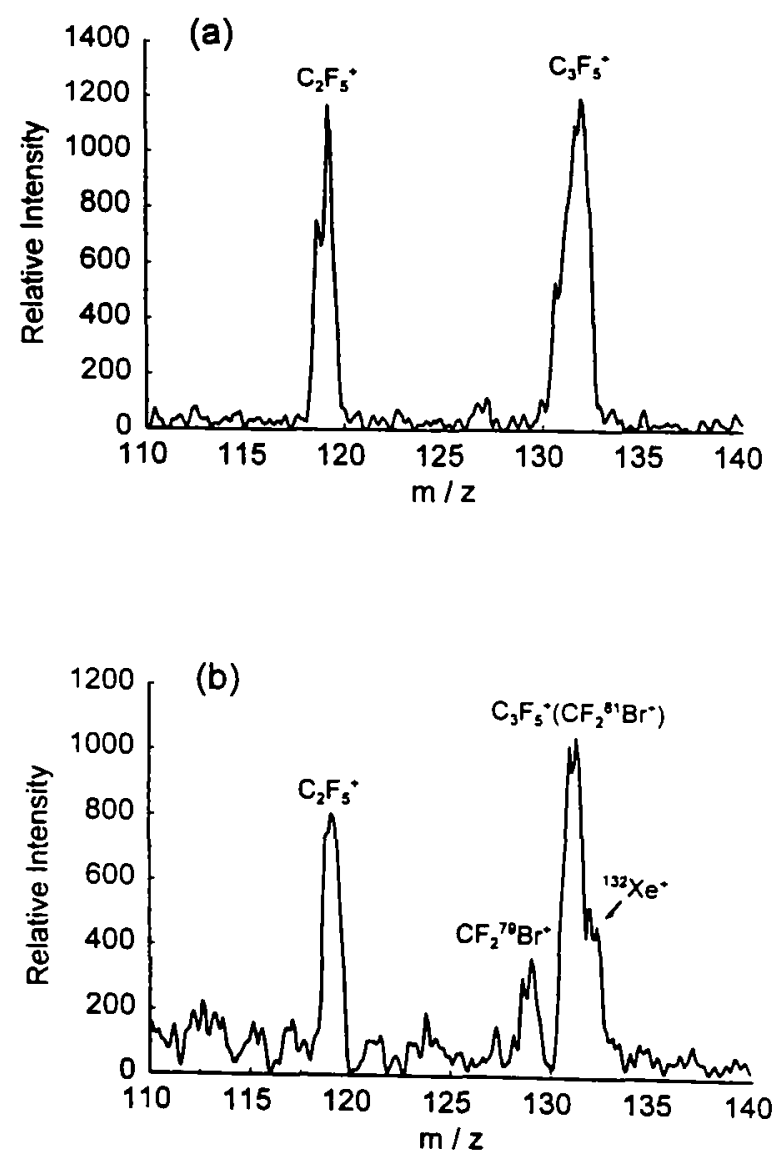

Figure 4. Partial chemical sputtering spectra recorded upon $60-\mathrm{eV}$ collision of ${ }^{132} \mathrm{Xe}^{+}$at a fluorinated SAM surface (a) before and (b) after bombardment with 60-eV CH ${ }_{2}^{79} \mathrm{Br}^{+}$(mass selected $m / z 93$ from $\mathrm{CH}_{2} \mathrm{Br}_{2}$ ) for $2 \mathrm{~h}$. Note the appearance of the peak at $m / z 129$ in (b). Alternative species given in parentheses are discussed in the text.

corresponds to the fragment $\mathrm{PCl}^{+\cdot}$ was observable at $m / z 66$ in the chemical sputtering spectra indicates that it is highly unlikely that $m / z 85$ represents $\mathrm{PClF}^{+*}$ To achieve a similar result in $\mathrm{Cl}-$ for- $\mathrm{F}$ exchange, it took $2 \mathrm{~h}$ of bombardment with a $\mathrm{SiCl}_{4}^{++}$projectile (Figure $2 \mathrm{~b}$ ), but only $20 \mathrm{~min}$ with a $\mathrm{PCl}_{3}^{++}$projectile (Figure 6b). With a $\mathrm{C}^{79} \mathrm{Br}_{3}^{+}$projectile, 20-min bombardment showed no evidence of significant Br-for- $\mathrm{F}$ halogen exchange, but after $2 \mathrm{~h}$, the expected product $\mathrm{CF}_{2} \mathrm{Br}^{+}$ was observed. Ion beam dose dependence indicates the rate differences for various surface processes that are involved in modification.

A study that used $\mathrm{P}^{35} \mathrm{Cl}^{+\cdot}$ projectile ions at $60-\mathrm{eV}$ collision energy showed $\mathrm{PF}^{+}$and $\mathrm{PClF}^{+}$as scattered ion-surface reaction products (Figure 7). Chemical sputtering peaks are also intense in this spectrum. It is difficult to determine the relative contribution of phosphorous and $C F$ to these peaks because they both have the mass of $31 \mathrm{u}$. However, based on previous results, formulas in parentheses in the figure represent the probable compositions of the minor components. The occurrence of extensive fluorine abstraction from the 

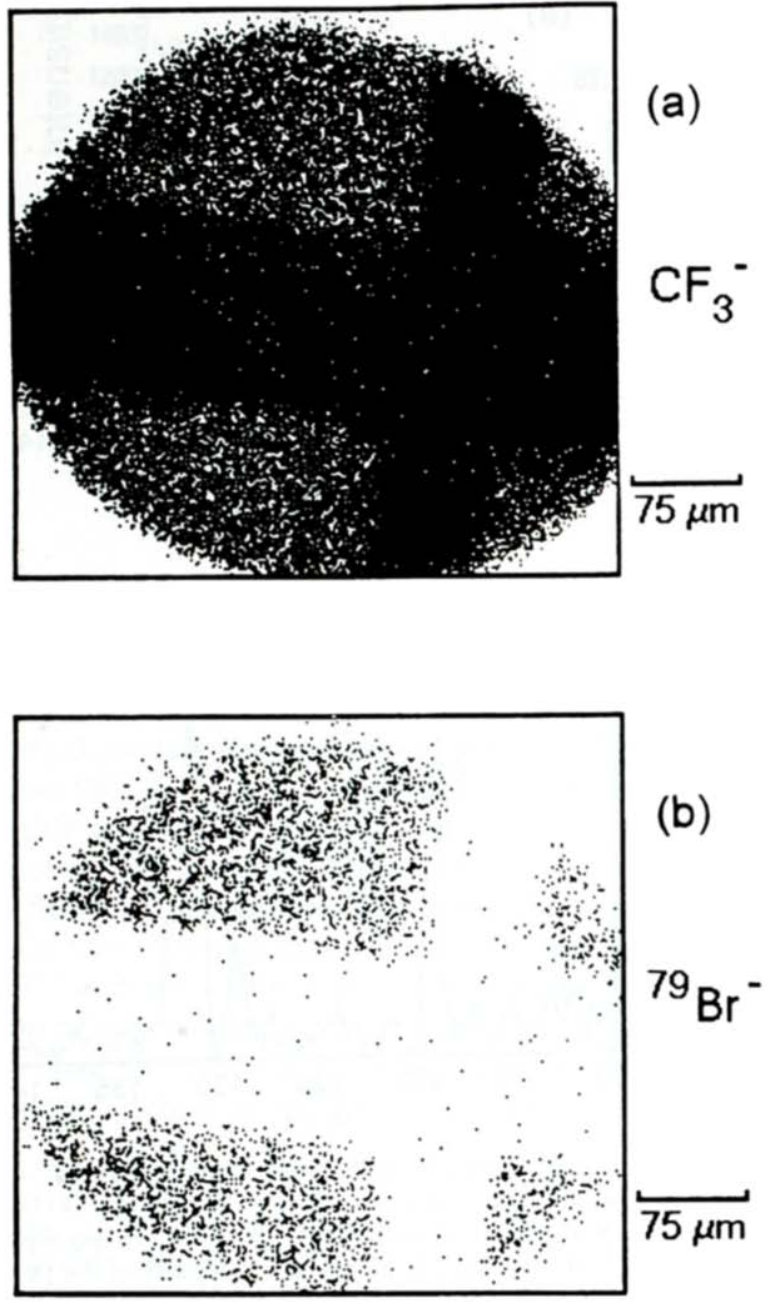

Figure 5. TOF-SIMS images $\left(25 \mathrm{keV}, \mathrm{Ga}^{+}\right)$of (a) $\mathrm{CF}_{3}^{-}$and (b) $\mathrm{Br}^{-}$from a C ${ }^{81} \mathrm{Br}^{+}$and $\mathrm{CH}_{2}{ }^{79} \mathrm{Br}^{+}$doublet $(m / z$ 93) bombarded fluorinated SAM surface. The ion beam was pattemed with a copper grid ( 50 mesh, $0.01-i n$. wire diameter). Note the decrease of $\mathrm{CF}_{3}^{-}$intensity and increase of $\mathrm{Br}^{-}$intensity in exposed relative to unexposed areas. (Darker regions represent higher intensity of species monitored.)

surface can be accompanied by its substitution with chlorine, as indicated by the presence of $\mathrm{CFCl}^{+\cdot}$ and $\mathrm{CF}_{2} \mathrm{Cl}^{+}$in the scattered ion beam. The surface itself was not examined in these experiments; however, model gas-phase ion-molecule reactions with a $\mathrm{PCl}^{+\cdot}$ projectile and $\mathrm{C}_{6} \mathrm{~F}_{14}$ collision gas were investigated. Product ion spectra showed the formation of $\mathrm{PClF}^{+}$, $\mathrm{PClF}_{2}^{+}, \mathrm{C}_{6} \mathrm{~F}_{12}^{+}$, and $\mathrm{C}_{6} \mathrm{~F}_{12} \mathrm{Cl}^{+}$as major features (Figure 8). This last species represents the gas-phase $\mathrm{Cl}$-for- $\mathrm{F}$ halogen substitution product and, as such, appears to arise by a process that is the analog of the process that takes place upon ion-surface collision.

A limited amount of thermochemical data that pertain to these ion-surface reactions is available. For example, the gas-phase reaction, $\mathrm{CH}_{2} \mathrm{Br}^{+}+\mathrm{CF}_{4} \rightarrow$ $\mathrm{CH}_{2} \mathrm{~F}^{+}+\mathrm{CF}_{3} \mathrm{Br}$ is endothermic by $43 \mathrm{kcal} / \mathrm{mol}$ [37]. In spite of its probable unfavorable thermochemistry, $\mathrm{CH}_{2} \mathrm{Br}^{+}$was found to undergo the Br-for-F substitu-
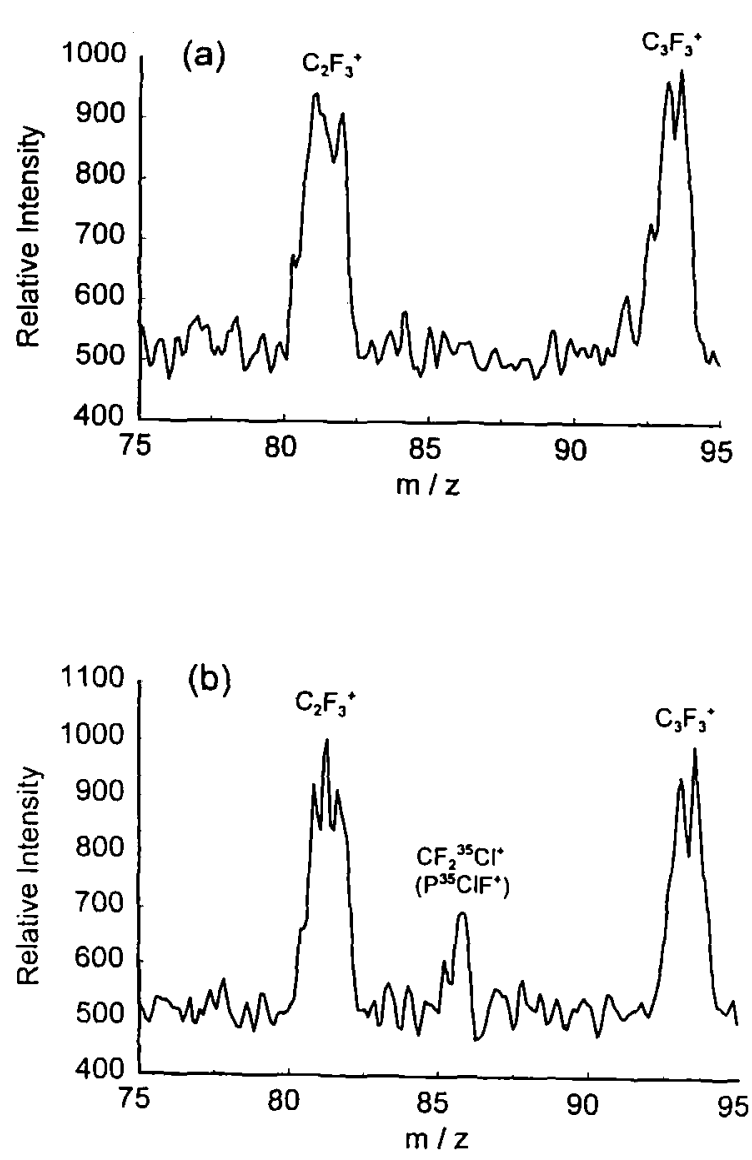

Figure 6. Partial chemical sputtering spectra recorded upon $60-\mathrm{eV}$ collision of ${ }^{132} \mathrm{Xe}^{+\cdot}$ at a fluorinated SAM surface (a) before and (b) after bombardment with $60-\mathrm{eV} \mathrm{P}^{35} \mathrm{Cl}_{3}^{+*}$ projectile for 20 min. Note the appearance of the peak at $m / z 85$ in (b). Alternative species given in parentheses are discussed in the text.

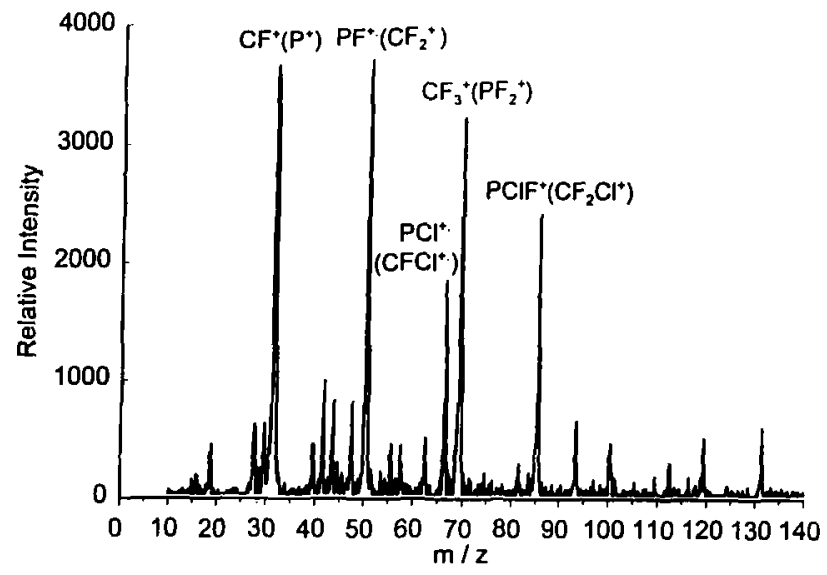

Figure 7. Scattered ion mass spectrum recorded upon $60-\mathrm{eV}$ collision of a $\mathrm{P}^{35} \mathrm{Cl}^{+\cdot}$ projectile at a fluorinated SAM surface. Note the relatively high intensity of ion-surface reaction products $\mathrm{PF}^{+}$and $\mathrm{PClF}^{+}$. Alternative species given in parentheses are discussed in the text. 


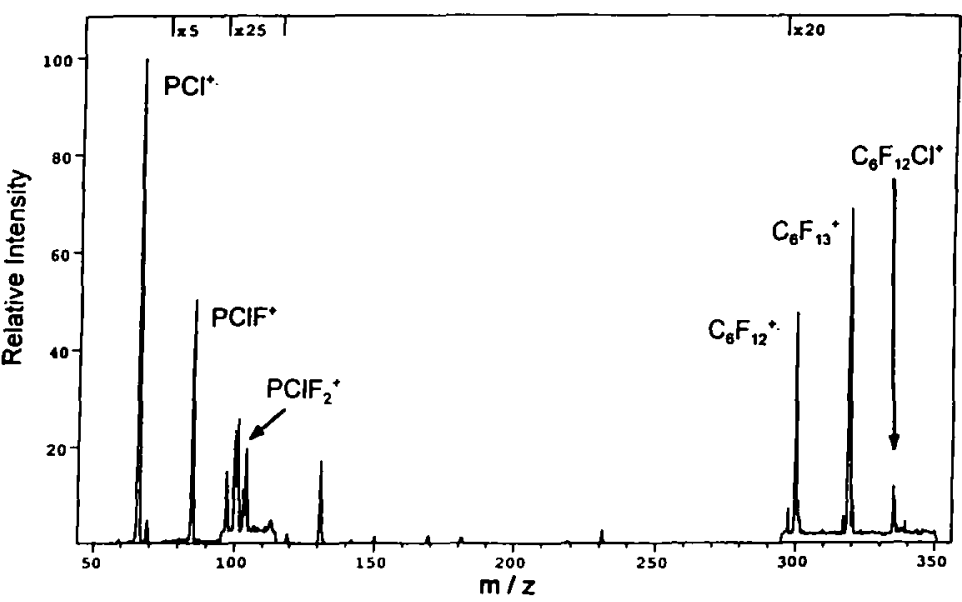

Figure 8. Partial product ion mass spectrum recorded upon gas-phase reaction between $\mathrm{P}^{35} \mathrm{Cl}^{+}$and $\mathrm{C}_{6} \mathrm{~F}_{14}$ at 2-eV translational energy and 1-mtorr pressure in the second quadrupole in a triple quadrupole mass spectrometer. Note the presence of peaks at $m / z 300$ and 335 due to $\mathrm{C}_{6} \mathrm{~F}_{12}^{+\cdot}$ and $\mathrm{C}_{6} \mathrm{~F}_{12} \mathrm{Cl}^{+}$, respectively. tion reaction in ion-surface collisions. This observation is in agreement with previous studies that indicate that F-SAM surfaces have a high efficiency of translational to internal energy transfer [24] and that thermodynamically unfavorable ion-surface reactions can be driven by the translational energy of the projectile ion [28].

\section{Conclusion}

The most important finding of this study is that chemically selective surface modification can be achieved by "soft landing" of ion beams. The results point toward the development of a form of chemical writing on surfaces in which patterns are written in the appropriate chemical functional groups. Subsequent reactions at the modified surfaces, that use more conventional techniques, might then be used to further modify these sites. Exciting possible applications for such materials can be expected to exist in nanomagnetism, nonlinear optics, molecular electronics, and structure-based molecular design [38-41].

Some information on the mechanisms of ion-surface reactive collisions is already available [42-47] from studies of the scattered ionic products. In particular, the fluorine atom abstraction process has been suggested to occur by an oxidative addition mechanism. In this study, we have shown that associated selective chemical changes are induced at the surface and that surface analysis can reveal the processes that take place. Of particular interest is the case of formal halogen transfer between the projectile ion and the surface, for which evidence is presented from examination of both the scattered ion beam and the surface. In addition, the analogous gas-phase reaction has been shown to occur. More detailed mechanistic studies, such as confirmation of the proposed fluoronium ion intermediate, still await exploration.

\section{Acknowledgment}

This work was supported by the National Science Foundation (CHE 92-233791).

\section{References}

1. Rabalais, J. W.; Kasi, S. Science 1988, 239, 623-625.

2. Smidt, F. A. CHEMTECH 1989, 19, 309-314.

3. Wilson, R. G.; Brewer, G. R. Ion Beams with Application to Ion Implantation; Wiley: New York, 1973.

4. Amirav, A.; Danon, A. Int. I. Mass Spectrom. Ion Processes 1990, 97, 107-113.

5. Scoles, G., Ed. Atomic and Molecular Beam Methods; Oxford University Press: Oxford, 1988.

6. Coburn, J. W. Pure Appl. Chem. 1992, 64, 709-713.

7. Lou, J.-C.; Oldham, W. G.; Kawayoshi, H.; Ling, P. J. Appl. Phys. 1992, 71, 3225-3230.

8. Kasi, S. R.; Kang, H.; Sass, C. S.; Rabalais, J. W. Surf. Sci. Rep. 1989, 10, 1-104

9. Ceyer, S. T. Science 1990, 249, 133-139.

10. Fenn, J. B. Pure Appl. Pliys. 1982, 43(5), 349-378.

11. Martin, J. S.; Greeley, J. N.; Morris, J. R.; Jacobs, D. C. J. Chem. Phys. 1992, 97, 9476-9479.

12. Akazawa, H.; Muruta, Y. J. Chem. Phys. 1990, 92, 5560-5568.

13. Willerding, B.; Heiland, W.; Snowdon, K. J. Phys. Rev. Lett. 1984, 53, 2031-2034.

14. Dekrey, M. J.; Mabud, Md. A.; Cooks, R. G.; Syka, J. E. P. Int. J. Mass Spectrom. Ion Processes 1985, 67, 295-303.

15. Lammert, S. A.; Cooks, R. G. J. Am. Soc. Mass Spectrom. 1991, $2,487-491$.

16. Riederer, D. E., Jr.; Miller, S. A.; Ast, T.; Cooks, R. G. I. Am. Soc. Mnss Spectrom. 1993, 4, 938-942.

17. Wysocki, V. H.; Ding, J.-M.; Jones, J. L.; Callahan, J. H.; King, F. L. J. Am. Soc. Mass Spectrom. 1992, 3, 27-32.

18. Li, G.; Duhr, A.; Wollnik, H. J. Am. Soc. Mass Spectrom. 1992, $3,487-492$

19. Le Meillour, S.; Cole, R.; Clairet, F.; Fournier, F.; Tabet, J. C.; Blasco, T.; Beaugrand, C.; Devant, G. Adv. Mass. Spectrom. $1989,11 A, 236-237$.

20. Williams, E. R.; Henry, K. D.; McLafferty, F. W.; Shabanowitz, J.; Hunt, D. F. J. Am. Soc. Mass Spectrom. 1990, 1, 413-416.

21. Wright, A. D.; Despeyroux, D.; Jennings, K. R.; Evans, S.; Riddoch, A. Org. Mass. Spectrom. 1992, 27, 525-526.

22. Ijames, C. F.; Wilkins, C. L. Anal. Chem. 1990, 62, 1295-1299.

23. Williams, E. R.; Jones, G. C., Jr.; Fang, L.; Zare, R. N.; Garrison, B. J.; Brenner, D. W. I. Am. Chem. Soc. 1992, 114, 3207-3210.

24. Morris, M. R.; Riederer, D. E., Jr.; Winger, B. E.; Cooks, R. G.; Ast, T.; Chidsey, C. E. D. Int. J. Mass Spectrom. Ion Processes 1992, 122, 181-217.

25. Somogyi, A.; Kane, T. E.; Ding, J.-M.; Wysocki, V. H. J. Am. Chem. Soc. 1993, 115, 5275-5283. 
26. Wu, Q.; Hanley, L. I. Plyys. Chem. 1993, 97, 2677-2685.

27. Pradeep, T.; Riederer, D. E., Jr.; Hoke S. H., II; Ast, T.; Cooks, R. G.; Linford, M. R. J. Am. Chem. Soc. 1994, 116, 8658-8665.

28. Pradeep, T.; Ast, T.; Cooks, R. G.; Feng, B. I. Pllys. Chem. 1994, 98, 9301-9311.

29. Chidsey, C. E. D.; Liu, G.-Y.; Rowntree, P.; Scoles, G. J. Chem. Plyys. 1989, 91, 4421-4423.

30. Porter, M. D.; Bright, T. B.; Allara, D. L.; Chidsey, C. E. D. I. Am. Chem. Soc. 1987, 109, 3559-3568.

31. Winger, B. E.; Laue, H.-J.; Horning, S. R.; Julian, R. K. Lammert, S. A.; Riederer, D. E., Jr.; Cooks, R. G. Rer. Sci Instrum. 1992, 63, 5613-5625.

32. Vincenti, M.; Cooks, R. G. Org. Mass Spectrom. 1988, 23. 317-326.

33. Cooks, R. G.; Ast, T.; Mabud, Md. A. Int. I. Mass Spectrom. lon Processes 1990, 100, 209-265.

34. (a) Frisbie, C. D.; Wollman, E. W.; Martin, J. R.; Wrighton, M. S. J. Vac. Sci. Technol. A 1993, 11, 2368-2372. (b) Frisbie, C. D.; Martin, J. R.; Duff, Jr., R. R.; Wrighton, M. S. I. Am. Chem. Soc. 1992, 114, 7142-7145.

35. Tarlov, M. J.; Newman, J. G. Langmuir 1992, 8, 1398-1405.
36. Alves, C. A.; Porter, M. D. Langmuir 1993, 9, 3507-3512.

37. Lias, S. G.; Bartmess, J. E.; Liebman, J. F.; Holmes, J. L.; Levin, R. D.; Mallard, W. G. I. Chem. Phys. Ref. Data 1988, 17 Suppl. 1.

38. Hernando, A., Ed. Nanomagnetism; Kluwer Academic: Boston, 1993.

39. Boyd, R. W. Nonlinear Optics; Academic: Boston, 1992.

40. Aviram, A. Molecular Electronics-Science and Technology; American Institute of Physics: New York, 1992.

41. Kuntz, I. D.; Meng, E. C.; Shoichet, B. K. Acc. Chem. Res. 1994, 27, 117-123.

42. Rowe, G. K.; Creager, S. E. Langmuir 1991, 7, 2307-2312.

43. Pradeep, T.; Riederer, D. E., Jr.; Ast, T.; Cooks, R. G. Rapid Commun. Mass Spectrom. 1993, 7, 711-713.

44. Callahan, J. H.; Somogyi, A.; Wysocki, V. H. Rapid Commun. Mass Spectrom. 1993, 7, 693-699.

45. Wainhaus, S. B.; Burroughs, J. A.; Wu, Q.; Hanley, L. Anal. Chem. 1994, 66, 1038-1043.

46. Riederer, D. E., Jr.; Cooks, R. G.; Linford, M. R. Org. Mass Spectrom., in press.

47. Rabalais, J. W. Acc. Chem. Res. 1994, 27, 26-32. 